\title{
Ischemic Preconditioning for Liver Transplantation: A Systematic Review and Meta- Analysis of Randomized Controlled Trials
}

\author{
Lina Jakubauskiene $^{\mathrm{a}, \mathrm{b}} \quad$ Matas Jakubauskas $^{\mathrm{a}, \mathrm{b}} \quad$ Philipp Stiegler $^{\mathrm{a}}$ Bettina Leber $^{\mathrm{a}}$ \\ Peter Schemmer $^{\mathrm{a}}$ Kestutis Strupas ${ }^{\mathrm{b}}$ \\ ${ }^{a}$ General, Visceral and Transplant Surgery, Department of Surgery, Medical University of Graz, Graz, Austria; \\ ${ }^{b}$ Faculty of Medicine, Vilnius University, Vilnius, Lithuania
}

\section{Keywords}

Ischemic preconditioning · Liver transplantation · Extended criteria donors - Marginal grafts

\begin{abstract}
Background: In recent decades, liver transplantation (LTX) has increased the survival and quality of life of patients with end-stage organ failure. Unfortunately, LTx is limited due to the shortage of donors. A lot of effort is put into finding new ways to reduce ischemia-reperfusion injury (IRI) in liver grafts to increase the number of suitable organs procured from expanded-criteria donors (ECD). The aim of this study was to systematically review the literature reporting LTx outcomes when using ischemic preconditioning (IPC) or remote ischemic preconditioning (RIPC) to reduce IRI in liver grafts. Methods: A literature search was performed in the MEDLINE, Web of Science, and EMBASE databases. The following combination was used: "Liver" OR "Liver Transplantation" AND "Ischemic preconditioning" OR "occlusion" OR "clamping" OR "Pringle." The following outcome data were retrieved: the rates of graft primary nonfunction (PNF), retransplantation, graft loss, and mortality; stay in hospital and the intensive care unit; and postoperative serum liver damage parameters. Results: The initial search retrieved 4,522 potentially relevant studies. After evaluating 17 full-text articles, a total of 9 randomized controlled trials (RCTs) were included (7 IPC and 2 RIPC studies) in the qualitative synthesis; the metaanalysis was only performed on the data from the IPC studies. RIPC studies had considerable methodological differenc-
\end{abstract}

karger@karger.com www.karger.com/vis

Karger BOPEN ACCESS
(C) 2021 The Author(s)

Published by S. Karger AG, Basel

This is an Open Access article licensed under the Creative Common Attribution-NonCommercial-4.0 International License (CC BY-NC) (http://www.karger.com/Services/OpenAccessLicense), applicable to the online version of the article only. Usage and distribution for commercial purposes requires written permission. es. The meta-analysis revealed the beneficial effect of IPC when comparing postoperative aspartate aminotransferase (AST) corresponding to a statistically lower mortality rate in the IPC group (odds ratio [OR] 0.51; 95\% confidence interval [CI] 0.27-0.98; $p=0.04)$. Conclusion: IPC lowers postoperative AST levels and reduces the mortality rate; however, data on the benefits of RIPC are lacking.

(c) 2021 The Author(s)

Published by S. Karger AG, Basel

\section{Introduction}

In recent decades, liver transplantation (LTx) has increased the survival and quality of life of patients with end-stage organ failure by providing a potentially longterm treatment option $[1,2]$. Unfortunately, LTx is limited due to the shortage of donors. The organ donor pool can be extended by using expanded-criteria donors (ECD), who are older and have a higher prevalence of fatty liver [3]. Grafts from ECD are particularly susceptible to ischemia-reperfusion injury (IRI), resulting in higher primary nonfunction (PNF) rates that, in turn, lead to inferior transplant outcomes $[4,5]$. A lot of effort is put into finding new ways to reduce IRI during LTx to increase the number of suitable organs procured from ECD. Several methods to reduce IRI in LTx are under in-

L.J. and M.J. contributed equally to this article. 


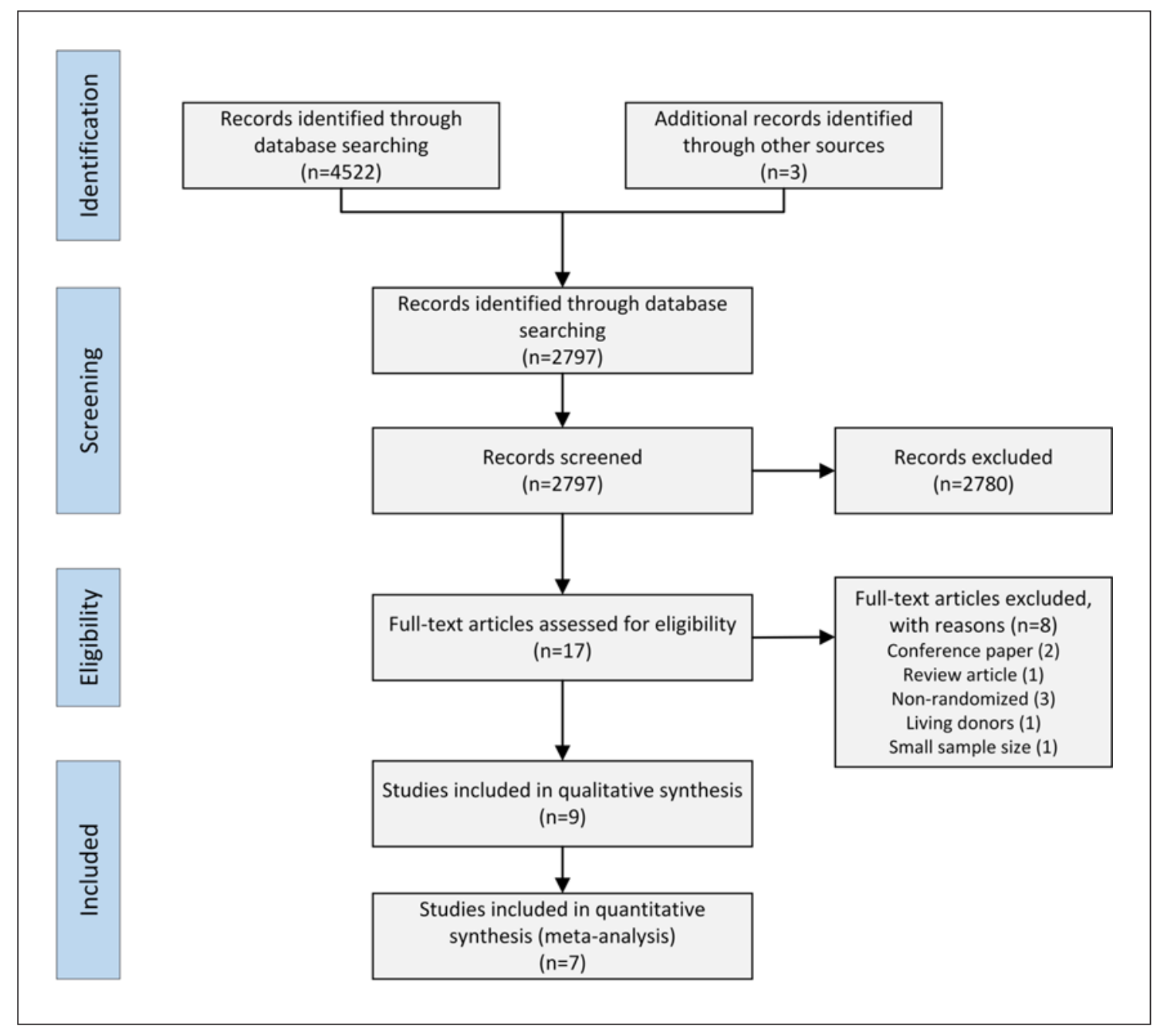

Fig. 1. PRISMA flowchart of study selection process.

vestigation, including new therapeutic agents to reduce IRI, graft perfusion and storage, and different ischemic preconditioning (IPC) strategies [6-9].

IPC describes a surgical method when a short period of ischemia to the target organ is supposed to lessen the harmful effects of IRI. It was first described in 1986 by Murry et al. [10] in a canine cardiac ischemia model and showed a protective effect on the myocardium. Over time, its use was investigated for multiple organs, including the liver [11-13]. The IPC technique for the liver is usually performed during procurement by a short inflow occlusion (the Pringle maneuver) followed by reperfusion. Preliminary data from animal studies showed beneficial effects of IPC in a LTx model, but its application in the clinical setting remains controversial [14]. A simpler procedure, when a short ischemia period is induced, not directly to the target organ but to a remote site (usually limb), causing systemic protection, is called remote (R) IPC. RIPC is a novel technique and its effectiveness in the transplantation setting remains unclear [15].
The aim of this paper was to systematically review the literature reporting LTx outcomes when using IPC or RIPC to reduce IRI in liver grafts.

\section{Methods}

\section{Literature Search Strategy}

The search was performed in the MEDLINE, Web of Science, and EMBASE databases. The following combination of $\mathrm{MeSH}$ terms and keywords (deploying the Boolean operators "AND" or "OR") were used: "Liver" OR "Liver Transplantation" AND "Ischemic preconditioning" OR "occlusion" OR "clamping” OR "Pringle."

The search was restricted to the English language and human studies only, but with no time limitation. The most recent search was performed on 21 September 2020. Database-specific search strategies are provided as online supplementary material (see www.karger.com/doi/10.1159/000516608 for all online suppl. material). 
Table 1. Characteristics and main findings of clinical regional IPC studies

\begin{tabular}{|c|c|c|}
\hline $\begin{array}{l}\text { First author } \\
\text { [ref.], year }\end{array}$ & $\begin{array}{l}\text { IPC group vs. controls, } \\
n\end{array}$ & IPC settings \\
\hline $\begin{array}{l}\text { Koneru } \\
{[11], 2005}\end{array}$ & 34 vs. 28 & $\begin{array}{l}\text { IPC time: } 5 \text { min early in the donor laparotomy, reperfusion length } \\
\text { n.r. Flushed with } 2 \text { L of } U W \circledR \text { cold storage solution via both the } \\
\text { portal vein and the aorta. }\end{array}$ \\
\hline $\begin{array}{l}\text { Cescon } \\
{[18], 2006}\end{array}$ & 24 vs. 23 & $\begin{array}{l}\text { IPC time: } 10 \mathrm{~min} \text {, followed by } 15 \mathrm{~min} \text { of reperfusion before starting } \\
\text { cold ischemia. Flushed with } 5 \mathrm{~L} \text { of Celsior } ® \text { solution through the } \\
\text { aorta and } 1 \mathrm{~L} \text { through the portal vein. }\end{array}$ \\
\hline $\begin{array}{l}\text { Amador } \\
{[19], 2007}\end{array}$ & 30 vs. 30 & $\begin{array}{l}\text { IPC time: } 10 \text { min, followed by } 10 \text { min of reperfusion before starting } \\
\text { cold ischemia. Flushed with } 2 \mathrm{~L} \text { of } \mathrm{UW} \text { solution through the aorta } \\
\text { and } 3 \mathrm{~L} \text { through the portal vein. }\end{array}$ \\
\hline $\begin{array}{l}\text { Koneru } \\
{[20], 2007}\end{array}$ & 50 vs. 51 & $\begin{array}{l}\text { IPC time: } 10 \text { min early in the donor laparotomy, reperfusion until } \\
\text { circulatory arrest. Flushed with } 2 \mathrm{~L} \text { of UW solution via both the } \\
\text { portal vein and the aorta. }\end{array}$ \\
\hline $\begin{array}{l}\text { Cescon } \\
{[21], 2009}\end{array}$ & 19 vs. 20 & $\begin{array}{l}\text { IPC time: } 10 \mathrm{~min} \text {, followed by } 15 \mathrm{~min} \text { of reperfusion before starting } \\
\text { cold ischemia. Flushed with } 5 \mathrm{~L} \text { of Celsior solution through the aorta } \\
\text { and } 1 \mathrm{~L} \text { through the portal vein. }\end{array}$ \\
\hline $\begin{array}{l}\text { Franchello } \\
{[22], 2009}\end{array}$ & 30 vs. 45 & $\begin{array}{l}\text { IPC time: } 10 \mathrm{~min} \text {, followed by } 30 \mathrm{~min} \text { of reperfusion before starting } \\
\text { cold ischemia. Preservation solution n.r. }\end{array}$ \\
\hline $\begin{array}{l}\text { Jassem } \\
{[23], 2009}\end{array}$ & 19 vs. 16 & $\begin{array}{l}\text { IPC time: } 10 \text { min early in the donor laparotomy, average reperfusion } \\
\text { length } 30 \text { min. Flushed with UW solution. }\end{array}$ \\
\hline
\end{tabular}

\section{Eligibility Criteria}

We included only randomized controlled trials (RCTs) with $>10$ patients per group, that investigated the use of IPC or RIPC in the LTx setting. Cohort studies, case-control studies, quasi-randomized studies, case reports, case series, and studies including children or animals were excluded.

\section{Study Selection and Data Extraction}

At first, the studies were screened based on their title and abstract. The full text was obtained for potentially eligible studies. The following data were extracted from all the included studies: study characteristics, year of publication, sample size, ischemic preconditioning parameters, and preservation solutions used. For the outcome assessment, additional data were obtained: the rates of graft PNF, retransplantation, graft loss, and mortality (for a maximum follow-up of 24 months); stay in hospital and the intensive care unit (ICU); and postoperative serum liver markers (aspartate aminotransferase $[\mathrm{AST}]$, alanine aminotransferase [ALT], total bilirubin, and international normalized ratio [INR]). If continuous variables were provided as medians, they were not included in the analysis due to concerns that the data were maybe skewed.

\section{Risk-of-Bias Assessment}

The quality of the included RCTs was evaluated using the RoB 2 risk-of-bias assessment tool, which is currently recommended in The Cochrane Handbook for Systematic Reviews and Interventions $[16,17]$.

\section{Statistical Analysis}

We performed the meta-analyses using the software package RevMan v5.3 according to the recommendations of The Cochrane
Handbook for Systematic Reviews and Interventions [17]. For dichotomous variables, we calculated the odds ratio (OR) and $95 \%$ confidence interval (CI). As we expected a high level of heterogeneity across studies, the Mantel-Haenszel (M-H) method and random-effects models were employed. For continuous variables, we calculated the mean difference using the inverse-variance (IV) method and random-effect models. Furthermore, the $I^{2}$ test was used to measure statistical heterogeneity. If a study observed no event in either group, it was not included in the quantitative analysis.

\section{Results}

\section{Study Selection and Characteristics}

Literature search results and the study selection process are presented in the PRISMA flowchart (Fig. 1). The initial search retrieved 4,522 potentially relevant studies. After evaluating 17 full-text articles, 9 were included in the qualitative synthesis $[11,18-25]$. Due to high heterogeneity between studies analyzing remote IPC $(n=2)$, only studies investigating regional IPC $(n=7)$ were included in the meta-analysis. Main characteristics of studies examining IPC and RIPC are presented in Tables 1 and 2, respectively. From the study by Jassem et al. [23], we only included AST levels at postoperative day 1 and 3 in the meta-analysis as other variables were not reported. 
Table 2. Characteristics and main findings of clinical remote IPC studies

\begin{tabular}{|c|c|c|c|}
\hline $\begin{array}{l}\text { First author } \\
\text { [ref.], year }\end{array}$ & $\begin{array}{l}\text { RIPC group vs. controls, } \\
n\end{array}$ & RIPC settings & Main findings \\
\hline $\begin{array}{l}\text { Robertson } \\
\text { [24] } 2017\end{array}$ & 20 vs. 20 & $\begin{array}{l}\text { Donor: deceased } \\
\text { Applied to: recipient } \\
\text { Place: left middle thigh } \\
\text { Applied pressure: } 200 \mathrm{~mm} \mathrm{Hg} \\
\text { Time: } 3 \text { cycles of } 5 \text { min each of } \\
\text { ischemia and reperfusion }\end{array}$ & $\begin{array}{l}\text { RIPC is feasible and acceptable in liver transplant recipi- } \\
\text { ents } \\
\text { No differences in clinical outcomes between RIPC and } \\
\text { control groups } \\
\text { Lower median IL- } 6 \text { level in the preconditioned group } \\
\text { compared to controls }\end{array}$ \\
\hline $\begin{array}{l}\text { Jung } \\
\text { [25] } 2020\end{array}$ & 75 vs. 73 & $\begin{array}{l}\text { Donor: living } \\
\text { Applied to: donor } \\
\text { Place: upper arm } \\
\text { Applied pressure: } 200 \mathrm{~mm} \mathrm{Hg} \\
\text { Time: } 3 \text { cycles of } 5 \text { min each of } \\
\text { ischemia and reperfusion }\end{array}$ & $\begin{array}{l}\text { No beneficial effect to the donor } \\
\text { Significantly lower AST levels on postoperative days } 1 \\
\text { and } 7 \text { in recipients with preconditioned grafts }\end{array}$ \\
\hline
\end{tabular}

Table 3. Risk-of-bias assessment of included RCTs using the RoB 2 tool

\begin{tabular}{|c|c|c|c|c|c|c|}
\hline $\begin{array}{l}\text { First author [ref.], } \\
\text { year }\end{array}$ & $\begin{array}{l}\text { Randomization } \\
\text { process }\end{array}$ & $\begin{array}{l}\text { Deviations from } \\
\text { intended intervention }\end{array}$ & $\begin{array}{l}\text { Missing data } \\
\text { on outcomes }\end{array}$ & $\begin{array}{l}\text { Measurement } \\
\text { of the outcome }\end{array}$ & $\begin{array}{l}\text { Selection of the } \\
\text { reported result }\end{array}$ & $\begin{array}{l}\text { Overall risk-of- } \\
\text { bias judgement }\end{array}$ \\
\hline \multicolumn{7}{|l|}{ IPC studies } \\
\hline Koneru [11], 2005 & low risk & low risk & low risk & low risk & some concerns & some concerns \\
\hline Cescon [18], 2006 & low risk & high risk & some concerns & low risk & some concerns & high risk \\
\hline Amador [19], 2007 & low risk & low risk & low risk & low risk & some concerns & some concerns \\
\hline Koneru [20], 2007 & low risk & low risk & low risk & low risk & some concerns & some concerns \\
\hline Cescon [21], 2009 & some concerns & some concerns & low risk & low risk & some concerns & some concerns \\
\hline Franchello [22], 2009 & some concerns & some concerns & low risk & low risk & some concerns & some concerns \\
\hline Jassem [23], 2009 & low risk & some concerns & low risk & low risk & some concerns & some concerns \\
\hline \multicolumn{7}{|l|}{ RIPC studies } \\
\hline Robertson [24], 2017 & low risk & low risk & low risk & low risk & some concerns & some concerns \\
\hline Jung [25], 2020 & low risk & low risk & low risk & low risk & some concerns & some concerns \\
\hline
\end{tabular}

\section{Study Quality}

All included RCTs, except one, were evaluated as having some concerns in the overall risk-of-bias judgement (Table 3). A study by Cescon et al. [18] was evaluated as having a high risk-of-bias due to the exclusion of some patients from the study, which may have influenced the final results.

\section{Outcome Assessment \\ IPC}

Mortality. The overall mortality rate was $9.7 \%(18 / 186)$ in the IPC group and $16.2 \%(32 / 198)$ in the control group. This difference was statistically significant (OR 0.51; 95\% CI $0.27-0.98 ; \mathrm{p}=0.04 ; I^{2}=0 \%$ ) (Fig. 2).

Graft Loss. Four trials reported graft loss rates [11, 18, $20,21]$. Our analysis showed a tendency that favors the IPC group (11.1\% [14/126] vs. 18.7 [23/123]), but the difference was not statistically significant (OR $0.54 ; 95 \% \mathrm{CI}$ $0.26-1.12 ; p=0.10 ; I^{2}=0 \%$ ) (Fig. 3 ). From the data reported by Amador et al. [19], we could not calculate graft loss events, so the study was not included in the quantitative analysis; this did not change the analysis outcome as the reported 24-month graft survival rate was similar between the groups (IPC $86.3 \%$ vs. controls $84.9 \%$ ).

$P N F$. The overall PNF rate in the IPC and control groups was $0.7 \%(1 / 152)$ and $4.1 \%(7 / 170)$, respectively. The analysis showed no difference between the groups (OR 0.38; 95\% CI 0.1-1.53; $p=0.18 ; I^{2}=0 \%$ ) (Fig. 4). A trial by Koneru et al. [11] reported no events in either group.

Retransplantation Rate. Similar retransplantation rates were observed when comparing the IPC and control groups (3.8\% [4/106] vs. 5.1\% [6/117]) with no statistical difference (OR $0.78 ; 95 \%$ CI $0.22-2.75 ; p=0.69 ; I^{2}=0 \%$ ) (Fig. 5).

Postoperative Serum Liver Markers. Only 3 studies reported mean postoperative AST levels. We did observe statistically significant differences between groups on postoperative days 1 and 3 (Fig. 6, 7). AST level differences equalized on postoperative day 7 (online suppl. Fig. 


\begin{tabular}{|c|c|c|c|c|c|c|c|c|c|c|}
\hline \multirow{2}{*}{$\begin{array}{l}\text { Study or Subgroup } \\
\text { Koneru [11] } 2005\end{array}$} & \multirow{2}{*}{$\begin{array}{r}\begin{array}{r}\text { IP } \\
\text { Events }\end{array} \\
3\end{array}$} & \multirow{2}{*}{$\begin{array}{r}\text { Total } \\
34\end{array}$} & Control & $\begin{array}{l}\text { ol } \\
\text { Total }\end{array}$ & Weight & \multirow{2}{*}{$\begin{array}{l}\text { Odds Ratio } \\
\text { M-H, Random, } 95 \% \mathrm{Cl}\end{array}$} & \multicolumn{4}{|c|}{$\begin{array}{c}\text { Odds Ratio } \\
\text { M-H, Random, } 95 \% \mathrm{Cl}\end{array}$} \\
\hline & & & 5 & 28 & $17.5 \%$ & & & & - & \\
\hline Cescon [18] 2006 & 0 & 23 & 2 & 24 & $4.3 \%$ & $0.19[0.01,4.21]$ & $\leftarrow$ & & & \\
\hline Amador [19] 2007 & 2 & 30 & 3 & 30 & $11.8 \%$ & $0.64[0.10,4.15]$ & & & & \\
\hline Koneru [20] 2007 & 11 & 50 & 17 & 51 & $52.1 \%$ & $0.56[0.23,1.37]$ & & 1 & - & \\
\hline Cescon [21] 2009 & 1 & 19 & 2 & 20 & $6.6 \%$ & $0.50[0.04,6.02]$ & & & & \\
\hline Franchello [22] 2009 & 1 & 30 & 3 & 45 & $7.7 \%$ & $0.48[0.05,4.87]$ & & & & \\
\hline Total $(95 \% \mathrm{Cl})$ & & 186 & & 198 & $100.0 \%$ & $0.51[0.27,0.98]$ & & & & \\
\hline Total events & 18 & & 32 & & & & & & & \\
\hline \multicolumn{6}{|c|}{$\begin{array}{l}\text { Heterogeneity: } \text { Tau }^{2}=0.00 ; \mathrm{Chi}^{2}=0.53, \mathrm{df}=5(P=0.99) ; \mathrm{I}^{2}=0 \% \\
\text { Test for overall effect: } Z=2.04(P=0.04)\end{array}$} & & 0.01 & 0.1 Favours IP & \begin{tabular}{|cc}
10 \\
Favours control
\end{tabular} & 100 \\
\hline
\end{tabular}

Fig. 2. Forest plot of studies comparing odds ratio of mortality rate between IPC and control groups.

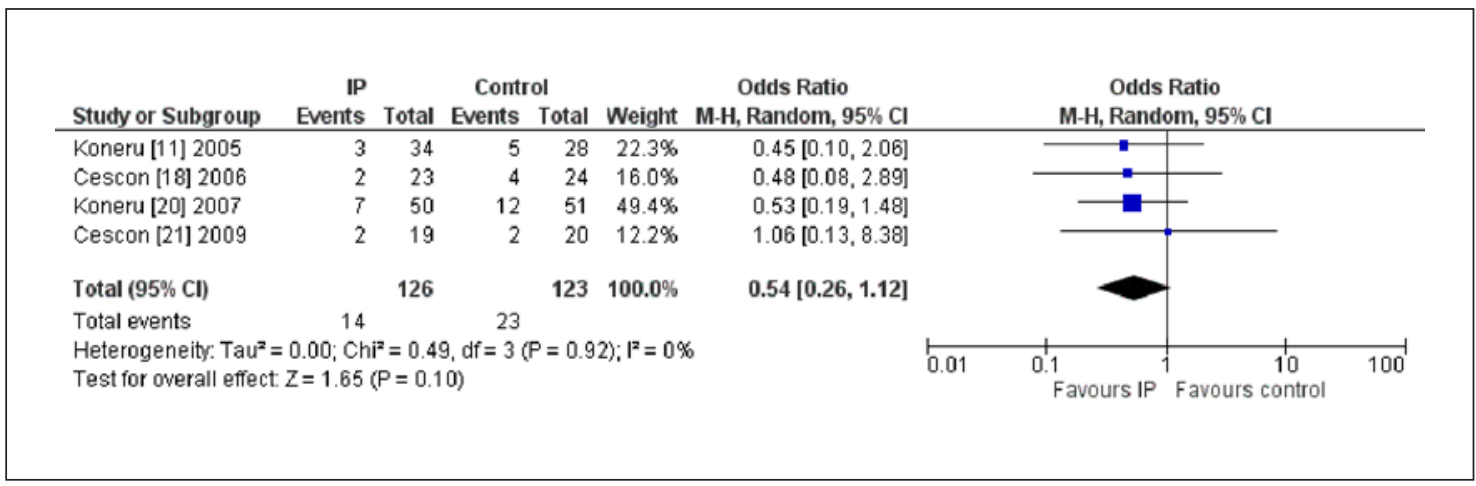

Fig. 3. Forest plot of studies comparing odds ratio of graft loss rate between IPC and control groups.

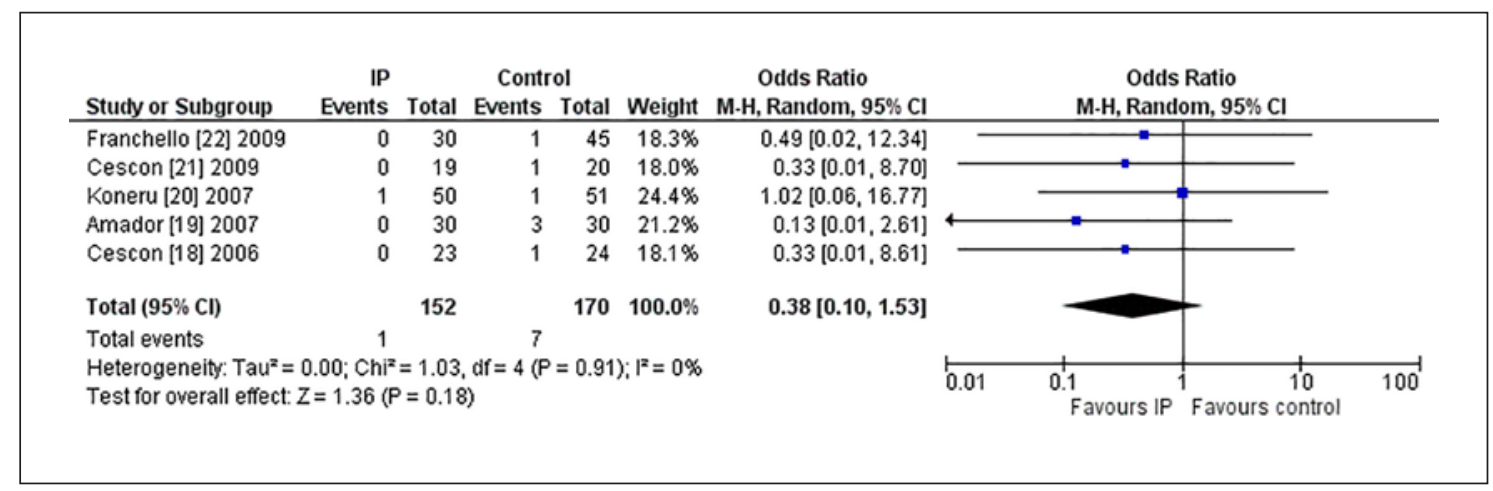

Fig. 4. Forest plot of studies comparing odds ratio of PNF rate between IPC and control groups.

S1). A similar tendency, favoring the IPC group, was observed with the ALT levels, but the differences were not significant (online suppl. Fig. S2, S3). INR and bilirubin levels were similar between groups during the postoperative period (online suppl. Fig. S4-S8).

Hospital and ICU Stay. There were no significant differences in the hospital and ICU staybetween the 2 groups (online suppl. Fig. S9, S10).

\section{RIPC}

Only 2 studies investigated the use of RIPC in the LTx setting (Table 2) [24, 25]. A pilot, double-blinded RCT was conducted by Robertson et al. [24] with transient ischemia periods in recipients. The primary end point of this study was to investigate whether RIPC is safe and feasible for LTx recipients. The authors concluded that RIPC was indeed safe and acceptable for the LTx recipients, but no clinical outcome differences were observed between 


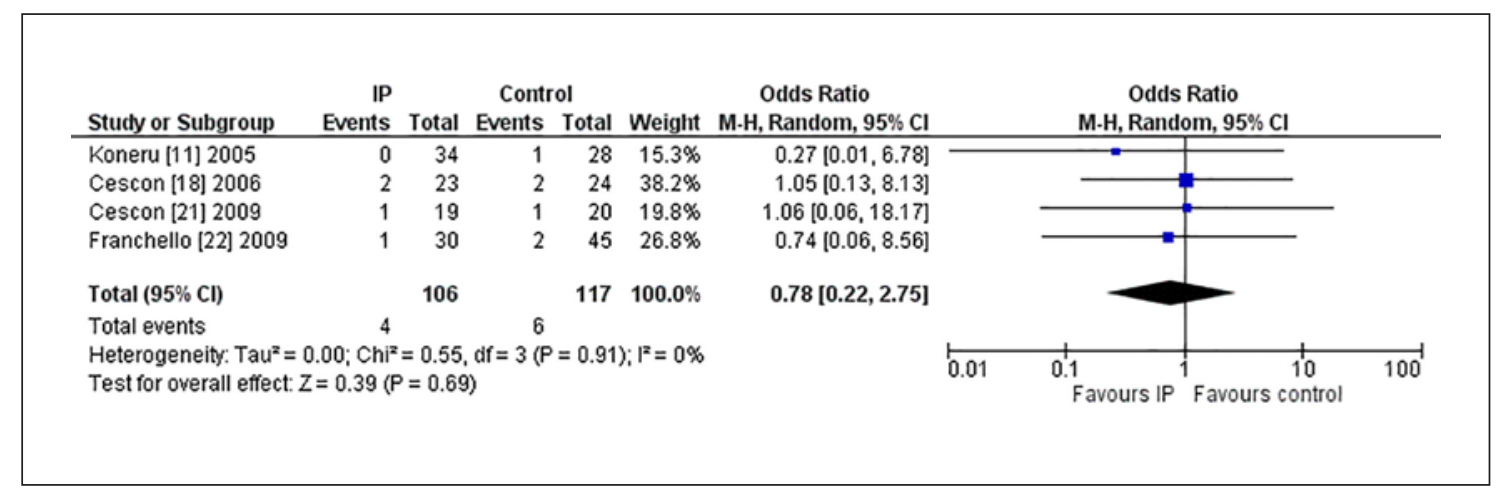

Fig. 5. Forest plot of studies comparing odds ratio of retransplantation rate between IPC and control groups.

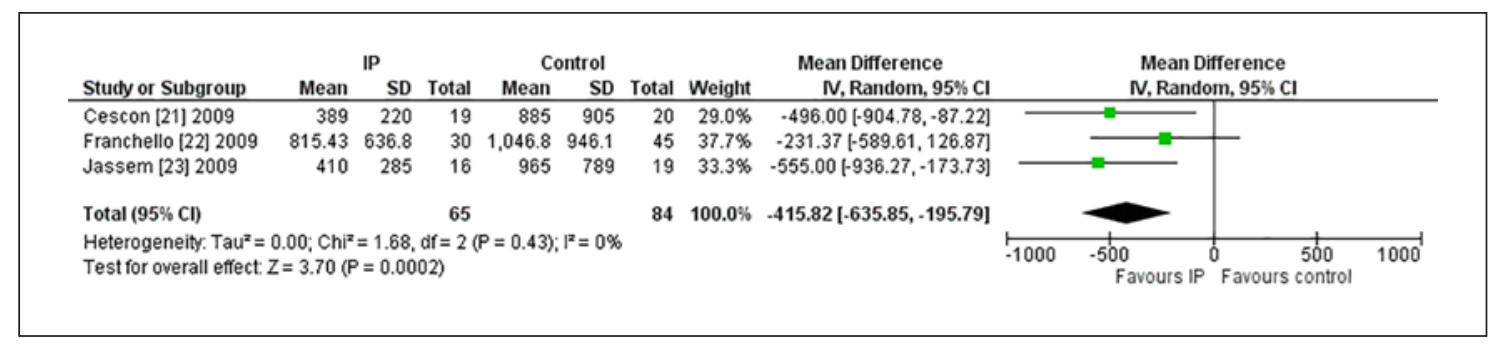

Fig. 6. Forest plot of studies comparing mean difference of AST levels on postoperative day 1 between IPC and control groups.

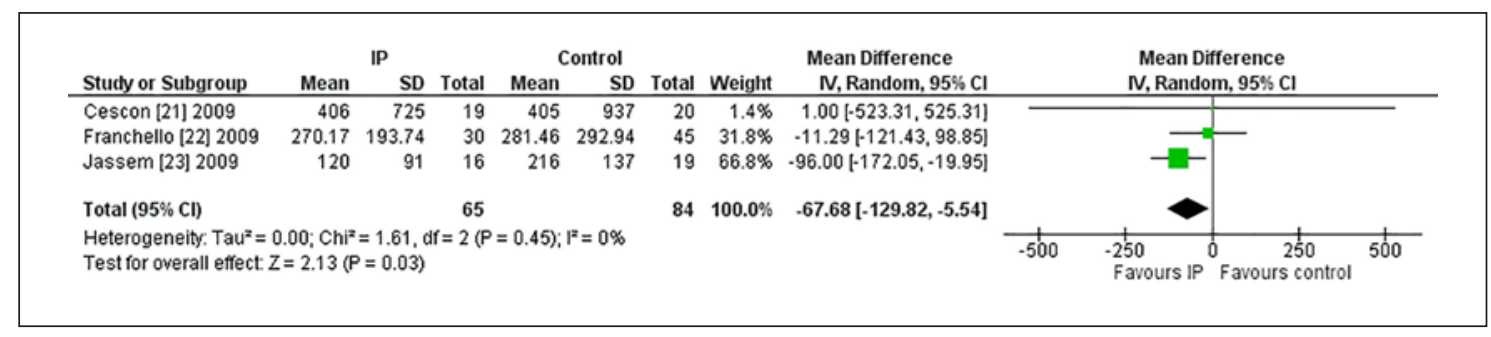

Fig. 7. Forest plot of studies comparing mean difference of AST levels on postoperative day 3 between IPC and control groups.

the groups. A very different RCT was published by Jung et al. [25]. In their trial, RIPC was applied to living donors. They did not find any RIPC benefits for the donors, but postoperative AST levels were significantly lower in recipients who received preconditioned grafts, indicating a beneficial effect of RIPC for the recipient.

\section{Discussion}

In this systematic review and meta-analysis, we provide an overview of the potential effects of IPC and RIPC on liver grafts during clinical LTx. The original aim was to perform a quantitative analysis on both IPC and RIPC RCTs, but methodological differences and the lack of RIPC studies limited the meta-analysis to IPC studies.

Our results revealed the beneficial effect of IPC when comparing postoperative AST levels between the groups. Furthermore, this corresponded to a statistically lower mortality rate in the IPC group. In addition, our study showed a tendency towards a lower graft loss rate in the IPC group, although the results were not statistically significant. These data are in line with the findings of Robertson et al. [26], who observed that AST levels on postoperative day 3 were closely related to the survival of the patient and the graft.

The exact mechanism involved in how IPC and RIPC reduce IRI remains unclear. Several studies indicate that there is a bimodal duration of protection $[27,28]$. The 
early protection period lasts up to $3 \mathrm{~h}$ and the later period lasts $12-72 \mathrm{~h}$ after preconditioning. Acting through humoral, systemic, and neuronal mechanisms, IPC and RIPC exert liver protection by reducing cell death and inflammatory response and improving the hepatic microcirculation [29]. Robertson et al. [29] provide an indepth overview of the possible protective mechanisms of IPC and RIPC in liver surgery.

Nowadays, as machine perfusion techniques are becoming more widely available, one could argue that the use of IPC and RIPC has lost its purpose in expanding the possible donor pool. However, the low cost and technical simplicity mean that IPC is still relevant, especially in centers where machine perfusion is not available. Furthermore, the 2 techniques could be combined and, potentially, yield even better results.

Unfortunately, it seems that the research interest in IPC has faded as the last RCT was published in 2009. On the other hand, the research of RIPC is becoming more popular as the 2 included RCTs were published in the last 3 years and we await results from other ongoing studies (NCT03758352 and NCT03855722) with interest.

Currently, there are 2 other meta-analyses on this topic. The first was published by Gurusamy et al. [14] in 2008; they included 5 RCTs and failed to show any benefits of IPC. The other was published by Robertson et al. [30] in 2016 and included both randomized and nonrandomized studies; they found that the IPC group had a significantly lower postoperative day 3 AST level. The main strength of our meta-analysis is that we included only RCTs with a moderate risk of bias when assessed with the RoB 2 tool.

Our analysis has some limitations. First, there is still no consensus about which IPC strategy is best for humans. As Table 1 shows, only 1 study induced transient ischemia for $5 \mathrm{~min}$, while the other RCTs used a 10-min time period. Moreover, there were some differences in the length of reperfusion.
The lack of beneficial IPC effect in the individual studies seems to be associated with graft quality. By performing a subgroup analysis, Franchello et al. [22] determined that IPC is beneficial to marginal grafts and showed no significant effect on the traditional grafts from DBD donors. The upcoming RCTs should focus more on the use of IPC on poor-quality liver grafts.

\section{Statement of Ethics}

The authors assert that all procedures contributing to this work comply with the ethical standards of the relevant national and institutional committees on human experimentation and with the Helsinki Declaration of 1975, as revised in 2008.

\section{Conflict of Interest Statement}

The authors have no conflicts of interest to declare.

\section{Funding Sources}

This research did not receive any specific grant from funding agencies in the public, commercial, or not-for-profit sectors.

\section{Author Contributions}

Conceptualization, P.Sc., P.St., B.L., and K.S.; methodology, M.J., L.J., P.Sc., and P.St.; software, M.J and L.J.; validation, P.Sc., P.St., and B.L.; formal analysis, M.J. and L.J.; investigation, M.J., L.J., P.Sc., P.St., B.L., and K.S.; resources, P.Sc., P.St., and B.L.; data curation, writing and original draft preparation, M.J. and L.J.; writing, review, and editing, P.Sc., P.St., B.L., and K.S.; visualization, M.J. and L.J.; supervision, P.Sc., P.St., B.L., and K.S.; project administration, P.Sc., P.St., and B.L.

\section{References}

1 Burra P, De Bona M. Quality of life following organ transplantation. Transpl Int. 2007 May;20(5):397-409.

2 Charlton MR. Improving long-term outcomes after liver transplantation. Clin Liver Dis. 2014 Aug;18(3):717-30.

3 McCormack L, Petrowsky H, Jochum W, Mullhaupt B, Weber M, Clavien PA. Use of severely steatotic grafts in liver transplantation: a matched case-control study. Ann Surg. 2007 Dec;246(6):940-6.

4 Verran D, Kusyk T, Painter D, Fisher J, Koorey $\mathrm{D}$, Strasser $\mathrm{S}$, et al. Clinical experience gained from the use of 120 steatotic donor livers for orthotopic liver transplantation. Liver Transpl. 2003 May;9(5):500-5.
5 Gabrielli M, Moisan F, Vidal M, Duarte I, Jiménez M, Izquierdo G, et al. Steatotic livers. Can we use them in OLTX? Outcome data from a prospective baseline liver biopsy study. Ann Hepatol. 2012 Nov-Dec;11(6):891-8.

6 Li DY, Liu WT, Wang GY, Shi XJ. Impact of combined ischemic preconditioning and remote ischemic perconditioning on ischemiareperfusion injury after liver transplantation. Sci Rep. 2018 Dec;8(1):17979.

7 Kahn J, Schemmer P. Comprehensive Review on Custodiol-N (HTK-N) and its Molecular Side of Action for Organ Preservation. Curr Pharm Biotechnol. 2017;18(15):1237-48.
8 Henry SD, Nachber E, Tulipan J, Stone J, Bae C, Reznik L, et al. Hypothermic machine preservation reduces molecular markers of ischemia/reperfusion injury in human liver transplantation. Am J Transplant. 2012 Sep; 12(9):2477-86.

9 Jakubauskiene L, Jakubauskas M, Leber B, Strupas K, Stiegler P, Schemmer P. Relaxin Positively Influences Ischemia-Reperfusion Injury in Solid Organ Transplantation: A Comprehensive Review. Int J Mol Sci. 2020 Jan;21(2):631.

10 Murry CE, Jennings RB, Reimer KA. Preconditioning with ischemia: a delay of lethal cell injury in ischemic myocardium. Circulation. 1986 Nov;74(5):1124-36. 
11 Koneru B, Fisher A, He Y, Klein KM, Skurnick J, Wilson DJ, et al. Ischemic preconditioning in deceased donor liver transplantation: a prospective randomized clinical trial of safety and efficacy. Liver Transpl. 2005 Feb;11(2):196-202.

12 Sola A, Alfaro V, Hotter G. Intestinal ischemic preconditioning: less xanthine accumulation relates with less apoptosis. Apoptosis. 2004 May;9(3):353-61.

13 Du ZY, Hicks M, Winlaw D, Spratt P, Macdonald $P$. Ischemic preconditioning enhances donor lung preservation in the rat. J Heart Lung Transplant. 1996 Dec;15(12):1258-67.

14 Gurusamy KS, Kumar Y, Sharma D, Davidson BR. Ischaemic preconditioning for liver transplantation. Cochrane Database Syst Rev. 2008 Jan;(1):CD006315.

15 Farooqui W, Pommergaard HC, Rasmussen A. Remote ischemic preconditioning of transplant recipients to reduce graft ischemia and reperfusion injuries: A systematic review. Transplant Rev (Orlando). 2018 Jan;32(1):10-5.

16 Sterne JA, Savović J, Page MJ, Elbers RG, Blencowe NS, Boutron I, et al. RoB 2: a revised tool for assessing risk of bias in randomised trials. BMJ. 2019 Aug;366:14898.

17 Higgins JPT, Thomas J, Chandler J, Cumpston M, Li T, Page MJ, Welch VA, editors. Cochrane Handbook for Systematic Reviews of Interventions. London: Cochrane; 2020. Available from: www.training.cochrane.org/handbook.

18 Cescon M, Grazi GL, Grassi A, Ravaioli M, Vetrone G, Ercolani G, et al. Effect of ischemic preconditioning in whole liver transplanta- tion from deceased donors. A pilot study. Liver Transpl. 2006 Apr;12(4):628-35.

19 Amador A, Grande L, Martí J, Deulofeu R, Miquel R, Solá A, et al. Ischemic pre-conditioning in deceased donor liver transplantation: a prospective randomized clinical trial. Am J Transplant. 2007 Sep;7(9):2180-9.

20 Koneru B, Shareef A, Dikdan G, Desai K, Klein KM, Peng B, et al. The ischemic preconditioning paradox in deceased donor liver transplantation-evidence from a prospective randomized single blind clinical trial. Am J Transplant. 2007 Dec;7(12):2788-96.

21 Cescon M, Carini R, Grazi G, Caraceni P, Alchera E, Gasloli G, et al. Variable activation of phosphoinositide 3-kinase influences the response of liver grafts to ischemic preconditioning. J Hepatol. 2009 May;50(5):937-47.

22 Franchello A, Gilbo N, David E, Ricchiuti A, Romagnoli R, Cerutti E, et al. Ischemic preconditioning (IP) of the liver as a safe and protective technique against ischemia/reperfusion injury (IRI). Am J Transplant. 2009 Jul;9(7):1629-39.

23 Jassem W, Fuggle S, Thompson R, Arno M, Taylor J, Byrne J, et al. Effect of ischemic preconditioning on the genomic response to reperfusion injury in deceased donor liver transplantation. Liver Transpl. 2009 Dec;15(12):1750-65.

24 Robertson FP, Goswami R, Wright GP, Imber C, Sharma D, Malago M, et al. Remote ischaemic preconditioning in orthotopic liver transplantation (RIPCOLT trial): a pilot ran- domized controlled feasibility study. HPB (Oxford). 2017 Sep;19(9):757-67.

25 Jung KW, Kang J, Kwon HM, Moon YJ, Jun IG, Song JG, et al. Effect of Remote Ischemic Preconditioning Conducted in Living Liver Donors on Postoperative Liver Function in Donors and Recipients Following Liver Transplantation: A Randomized Clinical Trial. Ann Surg. 2020 Apr;271(4):646-53.

26 Robertson FP, Bessell PR, Diaz-Nieto R, Thomas N, Rolando N, Fuller B, et al. High serum Aspartate transaminase levels on day 3 postliver transplantation correlates with graft and patient survival and would be a valid surrogate for outcome in liver transplantation clinical trials. Transpl Int. 2016 Mar;29(3): 323-30.

27 Hausenloy DJ, Yellon DM. Ischaemic conditioning and reperfusion injury. Nat Rev Cardiol. 2016 Apr;13(4):193-209.

28 Marber MS, Latchman DS, Walker JM, Yellon DM. Cardiac stress protein elevation 24 hours after brief ischemia or heat stress is associated with resistance to myocardial infarction. Circulation. 1993 Sep;88(3):1264-72.

29 Robertson FP, Fuller BJ, Davidson BR. An Evaluation of Ischaemic Preconditioning as a Method of Reducing Ischaemia Reperfusion Injury in Liver Surgery and Transplantation. J Clin Med. 2017 Jul;6(7):69.

30 Robertson FP, Magill LJ, Wright GP, Fuller B, Davidson BR. A systematic review and metaanalysis of donor ischaemic preconditioning in liver transplantation. Transpl Int. 2016 Nov;29(11):1147-54. 